\title{
Cancer mortality in relation to measures of occupational exposure to crocidolite at Wittenoom Gorge in Western Australia
}

\author{
N H de KLERK, ' B K ARMSTRONG, ${ }^{1}$ A W MUSK, ${ }^{2}$ M S T HOBBS ${ }^{3}$ \\ From the National Health and Medical Research Council Unit of Epidemiology and Preventive Medicine,' \\ Department of Medicine, University of Western Australia, the Department of Respiratory Medicine, ${ }^{2}$ \\ Sir Charles Gairdner Hospital, and Unit of Clinical Epidemiology, ${ }^{3}$ University of Western Australia, \\ Perth, Western Australia
}

\begin{abstract}
The separate and combined effects of duration and intensity of exposure to crocidolite on mortality from lung cancer, malignant mesothelioma, and stomach cancer were examined in 6506 male former crocidolite miners and millers at Wittenoom Gorge, Western Australia. Each subject who had died from lung cancer (92), mesothelioma (31), or stomach cancer (17) was matched with up to 20 control subjects of the same age who were not known to have died before the index subject. Relations of dose and time of exposure to crocidolite to risk of death were modelled by conditional logistic regression. For lung cancer, the best fitting multiplicative model was one which estimated a relative risk (RR) of $1.12(95 \%$ CI 1.04-1.20) per year of exposure and $1.01(95 \%$ CI 1.00-1.01) per fibre $/ \mathrm{ml}$. This was statistically indistinguishable from an additive model showing an increase in $R R$ of $0.01045(95 \%$ CI $0.008-0.020)$ per $\mathrm{f} / \mathrm{ml}$ year. For mesothelioma the best fitting model appeared to be one estimating a RR of $24.9(95 \%$ CI 3.51-177) per log year since first exposed and a RR of $10 \cdot 5(95 \%$ CI 3.12-35.1) if exposed for longer than six months. This was not distinguishable statistically from a model that showed mortality increasing as the fourth power of time since first exposed less the fourth power of time since last exposed. The effect of intensity of exposure on the RR for mesothelioma was only slight. There was no consistent effect of any measure of exposure to crocidolite on death from stomach cancer.
\end{abstract}

Current evidence shows that increasing cumulative exposure to either chrysotile or mixed asbestos fibres is associated with a linear increase in the incidence of lung cancer ${ }^{1-3}$ and that for equivalent doses the relative risk of disease is high among textile workers, possibly exposed to several types of asbestos, and low among friction product workers and asbestos cement workers using only chrysotile and among chrysotile miners. ${ }^{45}$ There exists at present no evidence concerning the form of the dose response relation between exposure to crocidolite alone and the incidence of lung cancer ${ }^{2-6}$ and how this may differ from the relation with chrysotile. . $^{-8}$

In addition, although it is accepted that the amphibole varieties of asbestos are much more potent in producing mesothelioma than chrysotile and that crocidolite appears to be the worst of the amphi-

Accepted 8 August 1988 boles, ${ }^{2-4}$ detailed reviews have shown that there is little reliable exposure response information available for the association of any form of asbestos with mesothelioma and none relating to crocidolite alone $\mathrm{e}^{2-468}$ apart from preliminary analyses of the data from Wittenoom Gorge, Western Australia. ${ }^{910}$

Debate still continues about the relation of asbestos with gastrointestinal cancers with several studies showing positive association. ${ }^{11-13}$ Whether the association is causal is uncertain; only one study has shown any evidence of a dose response relation. ${ }^{13}$

Increased death rates for malignant mesothelioma, lung cancer, and stomach cancer have previously been shown among former workers at the Wittenoom mine and mill who were exposed only to crocidolite. Results were presented in terms of SMRs, using rates of the Western Australian population as standard, and immediately age standardised rates were used to indicate how these rates changed with time since the start of exposure to crocidolite within groupings of 
total cumulative exposure. To quantify the exposure response relations between crocidolite and the three types of cancer discussed the data have been reanalysed using comparisons within the cohort to avoid some of the problems associated with the use of SMRs. ${ }^{1415}$

\section{Subjects}

A cohort of 6506 male former employees of the Australian Blue Asbestos Co who were employed in the mining or milling of crocidolite at Wittenoom Gorge between 1943 and the end of operations in 1966 was followed up to 31 December $1980 .^{9}$ Vital status at the end of follow up was known for $73.2 \%$ of the men. A group of 411 female employees was too small to be included in this analysis.

\section{Methods}

Demographic and basic exposure data were obtained from employment records supplemented, when incomplete, by records of the Perth Chest Clinic, which took compulsory pre-employment and periodic subsequent chest $x$ ray examinations of the men (both miners and millers), and by records of the Western Australian Mineworkers Relief Fund, a compulsory benevolent fund to which the company paid monthly subscriptions for each employee. These data included date of birth, nationality, and date and occupation at the beginning and date at the end of each period of employment.

The concentrations of airborne respirable fibres of crocidolite greater than $5 \mu \mathrm{m}$ in length were measured at various work sites in $1966 .{ }^{16}$ These measurements were used to obtain estimates of fibre concentrations for all 87 job categories in the various worksites. A subjective ranking of the degree of dustiness of these jobs, both before and after September 1957, when a less dusty mill began operating, had been provided by an ex-superintendent of operations at Wittenoom and verified by the industrial hygienist who conducted the 1966 survey. ${ }^{9}$ This scale was used to estimate fibre concentrations in earlier periods and in jobs not covered by the survey.

Three separate case-control analyses were performed. The cases were 17 men who had died from cancer of the stomach, 92 from cancer of the trachea, bronchus, and lung, and 31 from malignant mesothelioma. Controls were chosen from all men of exactly the same age who were not known to have died before the date of death of the index case. Up to 20 controls, if possible, were randomly chosen. If there were fewer than 20 men eligible to be selected then all eligible men were chosen as controls.

Conditional logistic regression analyses modelled the relative risk (or more correctly, the odds ratio) of de Klerk, Armstrong, Musk, Ho $\bar{b} b s$

death from each of the above cancers as a function $\overline{\text { of }}$ duration of employment, time weighted average estimated fibre concentration (calculated as क्षैe product of the time and fibre concentration in each job divided by the total duration of employment ${ }^{9}$ ), first employed, years since employment first began, worksite, and nationality. ${ }^{17}$ In this situation the ogds ratio (OR) closely approximates the relative risk (RR) and these two terms are used interchangeably throu out.

Variables were modelled individually and, where relevant, together, using the basic categorisatients shown in table 1 . The categorisations were modified for the analysis of pleural mesothelioma because of the few deaths from this condition in those employed sor $^{2}$ less than six months and within 15 years of fitst employment. The categorisation of duration of employment, fibre concentration, and years since $\mathrm{m}$ ployment began were arbitrary. The distribution;of year of first employment was broken at 1957 because of the introduction of the new mill in that year. Worksite was categorised into "ever mill," "ever mine but never mill," and "other" because of the supposed gradient in fibre concentrations, with median estimated time weighted fibre concentrations of 50 , 2 , and $5 \mathrm{f} / \mathrm{ml}$, respectively, for workers in these three groups.

Nationality rather than country of birth hadobegn recorded by the company. It is known that the "British" category included many men born in Agstralia who, presumably, as British subjects, consfered themselves to be British nationals, whereas ghe categories "Australian" and "Other" probably c\$ntained, respectively, mainly those born in Australia and those born in neither Australia nor Britain. $\overrightarrow{\overrightarrow{0}}$

Some exposure variables were also modelled continuously and the fit of these models was compared with their categorised counterparts only on the residūal deviance. ${ }^{18}$ The same approach was used for the comparison of additive and multiplicative models. $\stackrel{\mathbb{D}}{-}$

Previous work has shown that the effect of exposure to asbestos on the incidence of lung cancer may $\exists e$ represented approximately as follows:

$I_{1}=I_{0}^{*}(1+K * D * F)$

where $I_{1}$ is the incidence among asbestos work요 exposed for $D$ years to $F f / m l$, and $I_{0}$ is the incidentce rate in an unexposed population of the same age and smoking habit, and $\mathbf{K}$ is a constant. ${ }^{12}$ This model differs from the more usual multiplicative model soazn additive risk model of this form incorporating total cumulative exposure to asbestos instead of separate intensity and duration terms was also estimated for 画e relative risk of lung cancer.

Peto has postulated a model for the incidence $\mathbb{\leftrightarrow}_{\mathrm{O}}$ mesothelioma as follows, based on the multistage model of carcinogenesis':

$\mathrm{I}=\mathrm{K}^{*} \mathrm{~F}^{*}\left(\mathrm{~T}^{4}-(\mathrm{T}-\mathrm{D})^{4}\right)$ 
Table 1 Mortality from cancer of the trachea, bronchus, and lung by employment variables

\begin{tabular}{|c|c|c|c|c|c|}
\hline \multirow[b]{2}{*}{ Variable } & \multicolumn{2}{|c|}{ No of subjects (Mean values) } & \multicolumn{2}{|l|}{ Odds ratios } & \multirow[b]{2}{*}{ p Value } \\
\hline & Cases & Controls & Point estimate & $95 \% C I$ & \\
\hline $\begin{array}{l}\text { Days of employment: } \\
0-90 \\
91-183 \\
184-730 \\
731-1826 \\
\geqslant 1827 \\
\text { Years of employment* }\end{array}$ & $\begin{array}{l}34 \\
12 \\
20 \\
15 \\
11 \\
(1 \cdot 9)\end{array}$ & $\begin{array}{c}637 \\
304 \\
571 \\
205 \\
93 \\
(1 \cdot 2)\end{array}$ & $\begin{array}{l}1.0 \\
0.7 \\
0.7 \\
1.3 \\
2.2 \\
1.11\end{array}$ & $\begin{array}{l}0 \cdot 4-1 \cdot 6 \\
0 \cdot 4-1 \cdot 1 \\
0.7-2 \cdot 5 \\
1 \cdot 1-4 \cdot 5 \\
1 \cdot 04-1 \cdot 19\end{array}$ & $\begin{array}{l}0.03 \\
0.008\end{array}$ \\
\hline $\begin{array}{l}\text { Estimated average } \mathrm{f} / \mathrm{ml} \text { at worksites: } \\
0-9.9 \\
10-19.9 \\
20-49.9 \\
\geqslant 50 \\
\text { Missing } \\
\text { Average } \mathrm{f} / \mathrm{ml}^{*}\end{array}$ & $\begin{array}{l}20 \\
20 \\
20 \\
19 \\
13 \\
(34)\end{array}$ & $\begin{array}{l}423 \\
502 \\
335 \\
282 \\
268 \\
(26)\end{array}$ & $\begin{array}{l}1.0 \\
0.9 \\
1.3 \\
1.5 \\
1.0 \\
1.01\end{array}$ & $\begin{array}{l}0.5-1 \cdot 6 \\
0.7-2 \cdot 4 \\
0.8-2 \cdot 8 \\
0.5-2 \cdot 1 \\
1.00-1 \cdot 01\end{array}$ & $\begin{array}{l}0.5 \\
0.05\end{array}$ \\
\hline $\begin{array}{l}\text { Work site: } \\
\text { Never mill or mine } \\
\text { Ever mill } \\
\text { Ever mine, never mill } \\
\text { Unknown }\end{array}$ & $\begin{array}{l}16 \\
29 \\
25 \\
22\end{array}$ & $\begin{array}{l}364 \\
504 \\
447 \\
495\end{array}$ & $\begin{array}{l}1.0 \\
1.4 \\
1 \cdot 3 \\
1.0\end{array}$ & $\begin{array}{l}0.7-2.5 \\
0.7-2.4 \\
0.5-2.0\end{array}$ & 0.7 \\
\hline $\begin{array}{l}\text { Year first employed: } \\
1943-9 \\
1950-6 \\
\geqslant 1957\end{array}$ & $\begin{array}{l}22 \\
41 \\
29\end{array}$ & $\begin{array}{l}456 \\
762 \\
592\end{array}$ & $\begin{array}{l}1.0 \\
1.1 \\
1.1\end{array}$ & $\begin{array}{l}0.7-2.0 \\
0.6-2.0\end{array}$ & 0.9 \\
\hline $\begin{array}{l}\text { Years since first employed: } \\
0-10 \\
11-20 \\
\geqslant 21 \\
\text { Nationality: }\end{array}$ & $\begin{array}{r}9 \\
46 \\
37\end{array}$ & $\begin{array}{l}198 \\
785 \\
827\end{array}$ & $\begin{array}{l}1.0 \\
1.3 \\
0.9\end{array}$ & $\begin{array}{l}0.5-3 \cdot 0 \\
0.4-2.3\end{array}$ & 0.4 \\
\hline $\begin{array}{l}\text { Australian } \\
\text { British } \\
\text { Other } \\
\text { Unknown }\end{array}$ & $\begin{array}{l}14 \\
29 \\
26 \\
23\end{array}$ & $\begin{array}{l}355 \\
487 \\
418 \\
550\end{array}$ & $\begin{array}{l}1.0 \\
1.5 \\
1.6 \\
1.0\end{array}$ & $\begin{array}{l}0.8-2.9 \\
0.8-3.1 \\
0.5-2.0\end{array}$ & $0 \cdot 3$ \\
\hline
\end{tabular}

*Odds ratios for and mean values in units of years of employment or $\mathrm{f} / \mathrm{ml}$.

where $\mathrm{K}$ depends on fibre type, size, $\mathrm{mix}$, and other site specific variables, $F$ is intensity of exposure in $\mathrm{f} / \mathrm{ml}, \mathrm{T}$ is years since first exposure, and $D$ is years of exposure. The term $\left(T^{4}-(T-D)^{4}\right)$ may be rewritten as:

$$
\begin{aligned}
& =4 \mathrm{DT}^{3}-6 \mathrm{D}^{2} \mathrm{~T}^{2}+4 \mathrm{D}^{3} \mathrm{~T}-\mathrm{D}^{4} \\
& =4 \mathrm{DT}^{3 *}\left(1-1 \cdot 5(\mathrm{D} / \mathrm{T})+(\mathrm{D} / \mathrm{T})^{2}-0 \cdot 25(\mathrm{D} / \mathrm{T})^{3}\right) \\
& \simeq 4 \mathrm{DT}^{3 *} \exp \left(-1 \cdot 5^{*}(\mathrm{D} / \mathrm{T})\right)
\end{aligned}
$$

Taking logs in equation [2] gives

$\log (\mathrm{I})=\log (\mathrm{K})+\log (\mathrm{F})+\log \left(\mathrm{T}^{4}-(\mathrm{T}-\mathrm{D})^{4}\right) . .[4]$ or, using equation [3],

$\log (\mathrm{I})=\log (\mathrm{K})+\log (\mathrm{F})+\log (\mathrm{D})+3 \log (\mathrm{T})$

$-1 \cdot 5^{*}(\mathrm{D} / \mathrm{T})$

Conditional logistic regression models the logarithm of the odds of disease. Different levels of different variables are compared using odds ratios or differences in log odds which approximately equal the logarithm of the incidence rate ratio of one group (say group 2) compared with the reference group (say group 1), either $\log \left(I_{2} / I_{1}\right)$ or $\log \left(I_{2}\right)-\log \left(I_{1}\right)$. A good fit should therefore be obtained using either $\log \left(\mathrm{T}^{4}-(\mathrm{T}-\mathrm{D})^{4}\right)$ from equation [4] giving a regression coefficient of the order of $1, \operatorname{or} \log (T), \log (D)$, and $(D / T)$ from equation [5] giving regression coefficients of the order of 1,3 , and -1.5 respectively.

\section{Results}

CANCER OF THE TRACHEA, BRONCHUS, AND LUNG There was no evidence of an increase in deaths from lung cancer for employment periods of under two years (table 1). Thereafter it increased with increasing duration of employment to an odds ratio of $2 \cdot 2(95 \%$ confidence interval (CI) 1-1-4.5) for five or more years $(\geqslant 1827$ days). With years of employment as a continuous variable the odds ratio was $1 \cdot 11$ a year $(\mathrm{CI} 1.04$ 1.19 ) with an increase in residual deviance of only 4.2 compared with that obtained using the four categories for duration of employment. The $p$ values were high for the effects of all the other variables on deaths from lung cancer from intensity of exposure measured on a continuous scale which gave an OR of 1.01 (CI 1.00 1.01) per extra $\mathrm{f} / \mathrm{ml}$. The residual deviance for this model was actually less than that of the categorised one by 0.8 with the removal of two extra terms. There was a small increase in the odds ratio for the period 11 to 20 years after first employment $(1 \cdot 3, \mathrm{CI} 0 \cdot 5-3 \cdot 0)$ and those of British and Other nationalities had odds ratios of 1.5 and 1.6 respectively but with $95 \%$ CIs including unity. There was little evidence that year of first employment or worksite had any effect on death from lung cancer. 
Inclusion of duration and intensity of exposure together as continuous variables in a single logistic regression model had little effect on the association between death from lung cancer and either variable, with odds ratios of 1.12 (CI 1.04-1.20) a year and 1.01 (CI $1.00-1.01)$ per $\mathrm{f} / \mathrm{ml}$ respectively. All other variables when added singly to this model gave high $\mathrm{p}$ values $(>0 \cdot 35)$. Years since first employed together with its interaction with intensity of exposure (but not either duration of exposure or total cumulative exposure), however, significantly improved the fit of this model $\left(\chi^{2}\right.$ on $\left.4 \mathrm{df}=11 \cdot 0, \mathrm{p}=0.03\right)$. The odds ratio for intensity of exposure was 1.02 (CI 1.00-1.03) per $\mathrm{f} / \mathrm{ml}$ for 10 to 20 years after first employment, whereas for the two other periods it was less than 1 but with CIs including 1.

The additive risk model of equation [1] (see Methods) appeared to fit the data slightly better with a reduction in residual deviance of 1.0 with 1 less term giving a value for $\mathrm{K}$ of 0.01045 (CI 0.0008-0.020). Further variables could not be added to this model because of the usual convergence problems experienced with additive models. ${ }^{19}$ The estimated value of $\mathrm{K}$ was remarkably similar to the 0.01 derived by Doll and Peto in their summary of results relating to chrysotile textile workers. ${ }^{6}$

Differences between the models are illustrated in fig 1 which shows the straight line change in relative risk with total cumulative exposure to crocidolite fibres for the final additive model, the curved changes in RR for three sample values of intensity of exposure using the continuous RR estimates obtained for duration and intensity combined in the same model as above-that is, 1.12 a year and 1.01 per $\mathrm{f} / \mathrm{ml}$ - and, finally, separate RR estimates for the 20 categories of intensity (omitting the "missing" category) by duration combined, using median cumulative exposure within each group and RRs obtained from table 1. Clearly these data indicate a much stronger effect for duration than for intensity of exposure with the offscale $R R$ for 20 years of employment at $5 \mathrm{f} / \mathrm{ml}$ compared with the much lower RR for one year of employment at $100 \mathrm{f} / \mathrm{ml}$. Given the clustering of RRs around 1 and cumulative exposures generally below $100 \mathrm{f} / \mathrm{ml}$ years it is clear why it is not easy to give a preference for one model over the other even though they are conceptually different.

\section{MALIGNANT MESOTHELIOMA OF THE PLEURA}

The relative risk of pleural mesothelioma, like lung cancer, was also related to duration of employment at Wittenoom (table 2). There were no deaths from mesothelioma in those employed for 90 days or less so this category was combined with the next to give a reference category of 0 to 183 days containing three deaths. All longer periods showed around a tenfold or

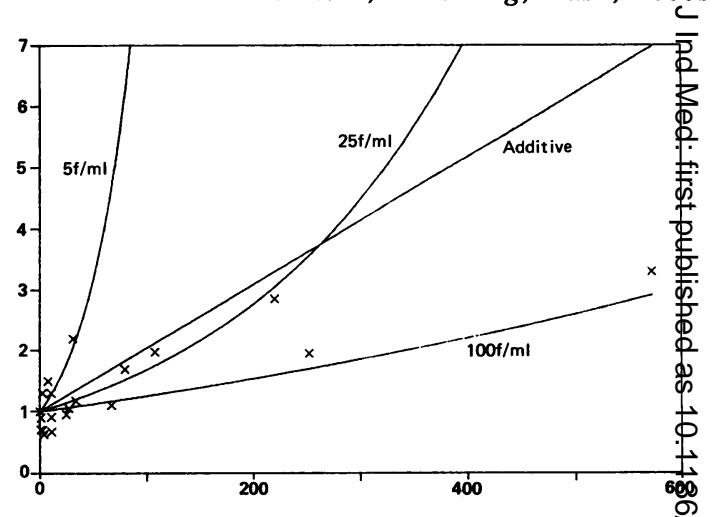

Fig 1 Change in relative risk of lung cancer by total cumulative exposure to crocidolite in $\mathrm{f} / \mathrm{ml}$ years for: (a) additive risk model, (b) continuous multiplicative risk modil at: (i) $5 \mathrm{f} / \mathrm{ml}$, (ii) $25 \mathrm{f} / \mathrm{ml}$, (iii) $100 \mathrm{f} / \mathrm{ml}$. Separate categor. estimates using RRs from table 1 . Abscissa = cumulative in crocidolite exposure $(f / m l y)$, ordinate $=$ relative risk.

higher increase in mortality with little indication of a gradient of increasing mortality with increasing dumation of employment.

There was strong evidence of a relation of death from mesothelioma with year first employed, with-a substantially lower mortality in those employed incer after 1957 (OR 0.2 CI 0.1-0.8) and time sinceofifst employment. With reference to $0-15$ years, mor after 16-20 years from first employment was incrềis eightfold and over 20 -fold for periods of greater:th 20 years from first employment.

Relative to other workers, there was weak eviden that mortality from mesothelioma of the pleura increased in those exposed to an average of 10 or more $\mathrm{f} / \mathrm{ml}$, in those who had ever worked in the mill, and in those who gave their nationality as other thẫn Australian.

Duration of employment and time since ffost employment were included together in a single regresssion model. Their mutually adjusted odds ratios were smaller but not greatly different in pattern from the unadjusted values (table 3). When each of the other variables was added in turn to this model the apparently lower mortality in those employed after 1956 disappeared (adjusted odds ratio 1.2, CI 0.2-8.6). The patterns of odds ratios in categories of the ot variables changed little, although the odds ratios level of exposure changed to $0 \cdot 4$ (CI 0.1-2.0) for the lowest category and 1.2 (CI 0.4-3.4) and 1.4 (CI 0 3.9) for the two higher categories, relative to the $\mathrm{k} \theta$ $19.9 \mathrm{f} / \mathrm{ml}$ category, with a $\mathrm{p}$ value for trend of $0.12 \mathrm{C}$

Fitting the single continuous variable log years sifee first exposed and a binary variable for whetiger exposed for longer than six months resulted in a reduction in the residual deviance of 0.9 even though 
Table 2 Mortality from malignant mesothelioma of the pleura by employment variables

\begin{tabular}{|c|c|c|c|c|c|}
\hline \multirow[b]{2}{*}{ Variable } & \multicolumn{2}{|c|}{ No of subjects (mean values) } & \multicolumn{2}{|l|}{ Odds ratios } & \multirow[b]{2}{*}{ p Value } \\
\hline & Cases & Controls & Point estimate & $95 \% C I$ & \\
\hline $\begin{array}{l}\text { Days of employment: } \\
\quad 0-183 \\
184-365 \\
366-730 \\
731-1826 \\
\geqslant 1827 \\
\text { Days of employment* } \\
\text { Estimated average } \mathrm{f} / \mathrm{ml} \text { at worksites: }\end{array}$ & $\begin{array}{c}3 \\
11 \\
10 \\
4 \\
3 \\
(6 \cdot 1)\end{array}$ & $\begin{array}{l}331 \\
88 \\
77 \\
56 \\
28 \\
(4 \cdot 9)\end{array}$ & $\begin{array}{r}1 \cdot 0 \\
13 \cdot 8 \\
13 \cdot 8 \\
8 \cdot 1 \\
11 \cdot 7 \\
1 \cdot 79\end{array}$ & $\begin{array}{l}3 \cdot 7-50 \cdot 8 \\
3 \cdot 7-51 \cdot 2 \\
1 \cdot 8-37 \cdot 0 \\
2 \cdot 2-62 \cdot 3 \\
1 \cdot 35-2 \cdot 36\end{array}$ & $\begin{array}{l}<0.001 \\
<0.001\end{array}$ \\
\hline $\begin{array}{l}0-9.9 \\
10-19.9 \\
20-49 \cdot 9 \\
\geqslant 50 \\
\text { Missing } \\
\text { Average fibres } / \mathrm{ml}^{*} \\
\text { Work site: }\end{array}$ & $\begin{array}{c}2 \\
11 \\
8 \\
8 \\
2 \\
(3 \cdot 1)\end{array}$ & $\begin{array}{l}97 \\
182 \\
136 \\
119 \\
46 \\
(2 \cdot 8)\end{array}$ & $\begin{array}{l}0.3 \\
1.0 \\
1.0 \\
1 \cdot 1 \\
0.7 \\
1 \cdot 26\end{array}$ & $\begin{array}{l}0 \cdot 1-1 \cdot 5 \\
0 \cdot 4-2 \cdot 6 \\
0 \cdot 5-2 \cdot 9 \\
0 \cdot 1-5 \cdot 1 \\
0.92-1 \cdot 72\end{array}$ & $\begin{array}{l}0 \cdot 5 \\
0 \cdot 1\end{array}$ \\
\hline $\begin{array}{l}\text { Never mill or mine } \\
\text { Ever mill } \\
\text { Ever mine, never mill } \\
\text { Unknown }\end{array}$ & $\begin{array}{r}4 \\
15 \\
7 \\
5\end{array}$ & $\begin{array}{r}79 \\
207 \\
162 \\
132\end{array}$ & $\begin{array}{l}1.0 \\
1.5 \\
0.9 \\
0.8\end{array}$ & $\begin{array}{l}0 \cdot 5-4 \cdot 8 \\
0 \cdot 2-3 \cdot 1 \\
0 \cdot 2-2 \cdot 9\end{array}$ & 0.5 \\
\hline $\begin{array}{l}\text { Year first employed: } \\
1943-9 \\
1950-6 \\
\geqslant 1957\end{array}$ & $\begin{array}{r}5 \\
19 \\
7\end{array}$ & $\begin{array}{r}68 \\
227 \\
285\end{array}$ & $\begin{array}{l}1 \cdot 0 \\
1.1 \\
0.2\end{array}$ & $\begin{array}{l}0.4-3.2 \\
0.1-0.8\end{array}$ & 0.007 \\
\hline $\begin{array}{l}\text { Years since first employed: } \\
\quad 0-15 \\
16-20 \\
21-25 \\
26-30 \\
\geqslant 31 \\
\text { Years since first employed* } \\
\text { Nationality: }\end{array}$ & $\begin{array}{c}2 \\
8 \\
13 \\
7 \\
1 \\
(3 \cdot 1)\end{array}$ & $\begin{array}{l}170 \\
165 \\
149 \\
83 \\
13 \\
(2 \cdot 9)\end{array}$ & $\begin{array}{r}1 \cdot 0 \\
8 \cdot 2 \\
19 \cdot 1 \\
22 \cdot 0 \\
23 \cdot 2 \\
33 \cdot 6\end{array}$ & $\begin{array}{l}1 \cdot 3-50 \cdot 5 \\
2 \cdot 9-127 \\
2 \cdot 9-167 \\
1 \cdot 3-399 \\
4 \cdot 9-229\end{array}$ & $\begin{array}{r}0.002 \\
<0.001\end{array}$ \\
\hline $\begin{array}{l}\text { Australian } \\
\text { British } \\
\text { Other } \\
\text { Unknown }\end{array}$ & $\begin{array}{r}3 \\
8 \\
12 \\
8\end{array}$ & $\begin{array}{l}112 \\
163 \\
180 \\
125\end{array}$ & $\begin{array}{l}1 \cdot 0 \\
1 \cdot 9 \\
2 \cdot 7 \\
2 \cdot 4\end{array}$ & $\begin{array}{l}0.5-7.4 \\
0.7-9.7 \\
0.6-9.2\end{array}$ & 0.4 \\
\hline
\end{tabular}

*Odds ratios for and mean values in units of $\log ($ days $), \log (\mathrm{f} / \mathrm{ml})$, or $\log ($ years $)$.

six fewer terms were estimated. The estimated odds ratios were $24.9(95 \%$ CI $3.51-177)$ per log year since first exposed and $10 \cdot 5(95 \%$ CI $3 \cdot 12-35 \cdot 1)$ if exposure was for six months or more. This model was only fitted after seeing the results from table 3 so its significance should be judged accordingly.

Two further logistic regression models based on equations [5] and [4] (see Methods) were constructed. The first contained the following three terms as continuous variables; log years since first exposure $(\log T), \log$ duration of exposure $(\log D)$, and duration/years since first exposure $(D / T)$. The regression coefficients obtained were 2.8 (SE 1.0) for $\log \mathrm{T}, 1 \cdot 1$ (SE 0.33 ) for $\log D$, and -7.7 (SE 3.8) for $D / T$, similar to those expected from equation [5]-that is, $3 \cdot 0,1 \cdot 0$, and -1.5 respectively.

A second model including only the single variable $\log \left(T^{4}-(T-D)^{4}\right)$ instead of the three continuous variables gave a slightly larger residual deviance and a regression coefficient of 0.73 (SE 0.15 ), similar to the coefficient of 1.0 expected from equation [4].

Addition of the average time weighted exposure to
Table 3 Associations between mortality from malignant mesothelioma of the pleura and duration of employment and time since employment began, considered together in two separate models

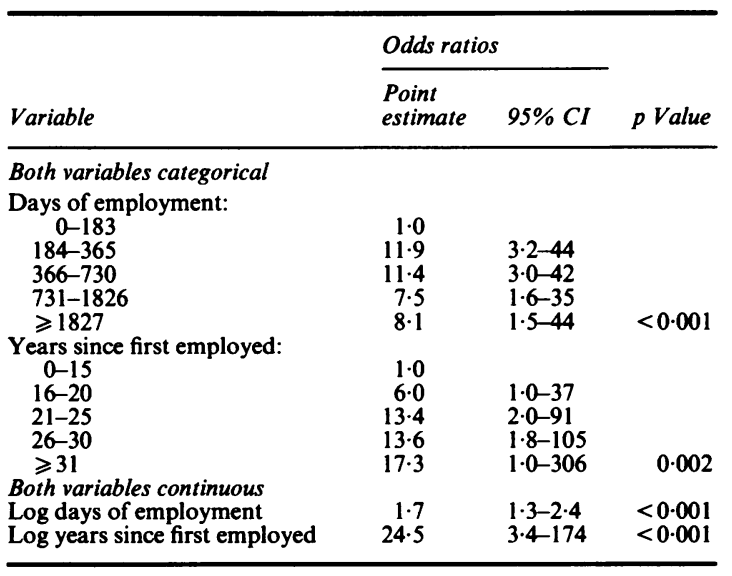

*p Value for removal from joint categorical or continuous model. 


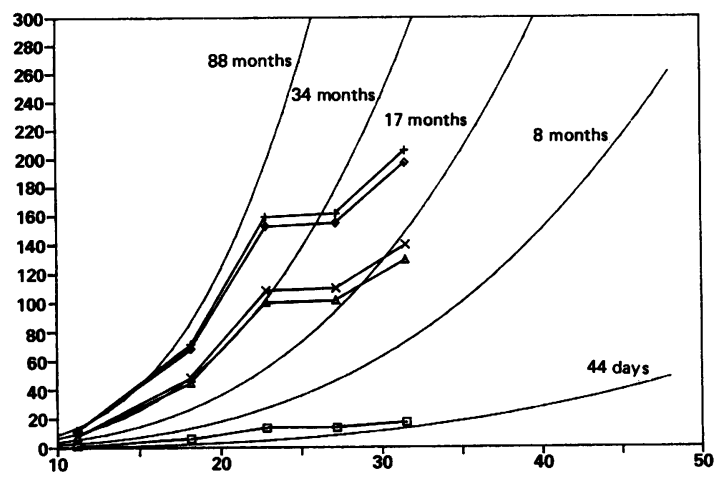

Fig 2 Change in relative risk of mesothelioma with time since first employed for five groups of duration of employment: $\square$ 0-183 days (median 44 days), + 184-365 days (median 8 months), $\diamond$ 366-730 days (median 17 months), $\triangle$ 731-1826 days (median 34 months), $\times \geqslant 1827$ days (median 88 months) for continuous risk estimates using equation [4] and separate category estimates from table 3. Median values for categories of time since first employed were; $11 \cdot 2,18 \cdot 2,22 \cdot 8,27 \cdot 2$, and $31 \cdot 5$ years. Abscissa $=$ years since first employed, ordinate $=$ relative risk.

all these models gave similar results. When added to the last one the odds ratios were, relative to the 10 $19.9 \mathrm{f} / \mathrm{ml}$ category, $0.4(\mathrm{CI} 0.1-1.8)$ for $<10 \mathrm{f} / \mathrm{ml}$, $1 \cdot 2(\mathrm{CI} 0.4-3.3)$ for $20-49.9 \mathrm{f} / \mathrm{ml}$, and $1.6(\mathrm{CI} 0.6-4.4)$ for $>50 \mathrm{f} / \mathrm{ml}$ with $\mathrm{p}$ value for trend of $0 \cdot 11$. Odds

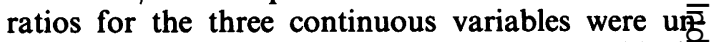
altered. When considered as a continuous variable the odds ratio was $1 \cdot 2(\mathrm{CI} 0 \cdot 8-1 \cdot 8)$ per $\log \mathrm{f} / \mathrm{ml}$ with $\mathrm{p}$ valuge $0 \cdot 3$.

Assigning median values to the categories of yea $\overrightarrow{\bar{F}}$ of employment and years since first employment, and taking as reference category the lowest category each (with median values 44 days and 11.2 yea respectively), curves of the change in $R R$ with yeans since first employed were estimated using equation [क्री and assuming constant fibre intensity $(\mathrm{F})$. These afe shown as curves in fig 2 together with the RRs obtained using the category estimates from Table $\dot{z}$ whereas the modelled values clearly differ from thes categorical values but not by a great deal. Most of these differences may be seen to lie with the lack of a increase in estimated RR for durations of exposure of longer than six months.

\section{CANCER OF THE STOMACH}

There was no strong evidence that mortality frop cancer of the stomach varied with any index of exposure to crocidolite or with any other measured variable (table 4). The strongest evidence for any effect of any variable was for worksite; the OR for employment in the mine but never in the mill was 37 $(0 \cdot 7-18)$ and the $p$ value for heterogeneity across ad categories of the variable was 0.08 . There was litte to

Table 4 Mortality from cancer of the stomach and employment variables

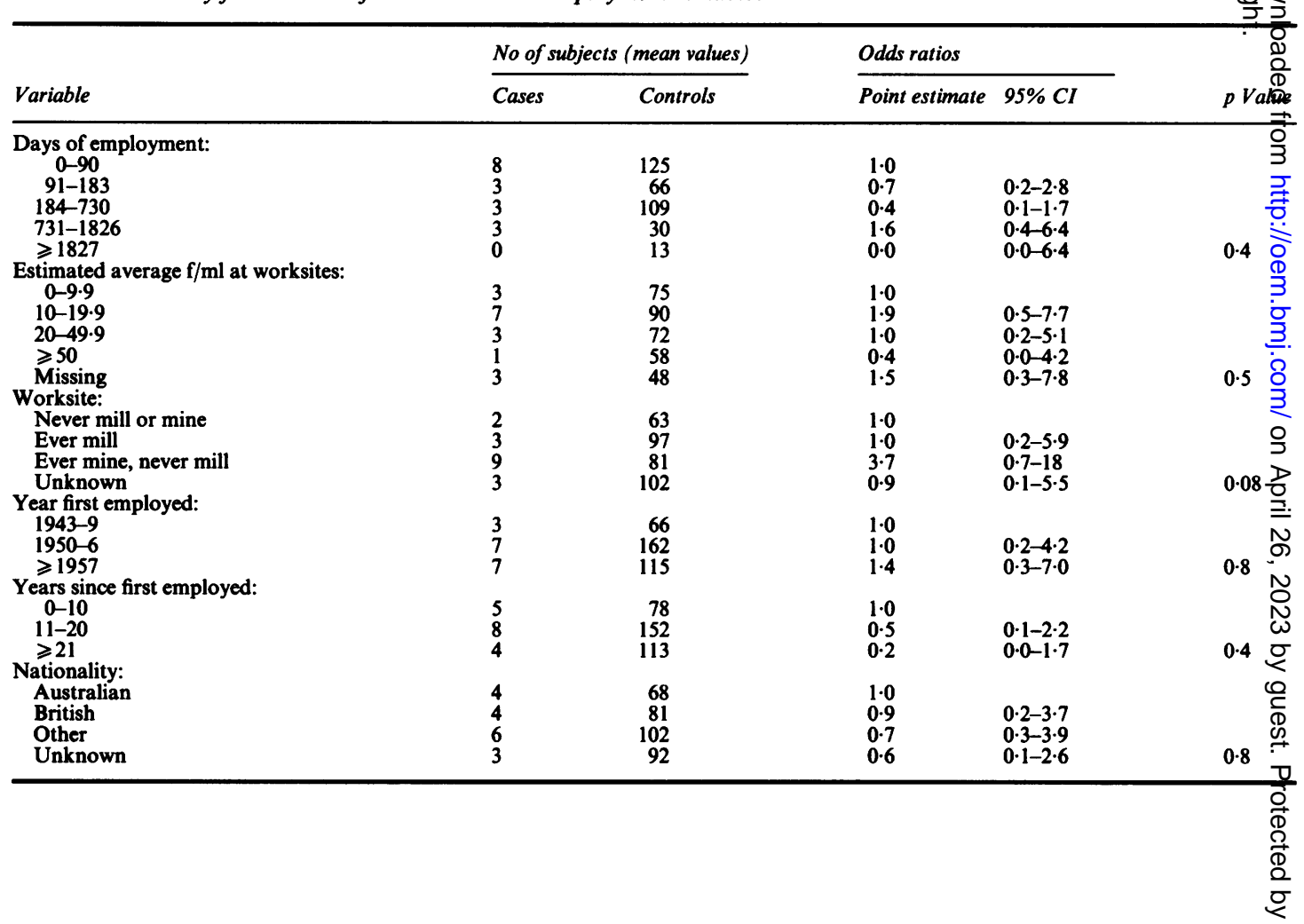


suggest that mortality from cancer of the stomach increased with either duration of employment or intensity of exposure to crocidolite. The effect of worksite was not altered by adjustment for any of the other variables. As an added check on the importance of the increased relative risk in the mine, a second random sample of controls was selected giving an OR of 2.0 with p value 0.25 .

\section{Discussion}

This study of the cohort of workers from Wittenoom Gorge shows that mortality from lung cancer increased significantly with increasing duration of employment and increasing intensity of exposure. The results were consistent with a model of the effect of these two variables in which their product added to rather than multiplied the baseline risk of lung cancer, as has been proposed by Peto, ${ }^{1}$ and were remarkably similar to results synthesised by Doll and Peto ${ }^{6}$ from the analysis of several cohorts exposed mainly to chrysotile or mixed asbestos fibres. ${ }^{6}$ It was impossible, however, to assess whether this model fitted the data any better than one where intensity and duration of exposure act independently to multiply the risk. There was also some evidence that the effect of exposure was greatest between 10 and 20 years after first employment. This was only related to intensity of exposure and was earlier than in other cohorts where the effect of cumulative exposure appeared to fall after 30 or more years from first exposure. ${ }^{2021}$ It is, however, consistent with the idea of asbestos acting at an intermediate or late stage in the development of lung cancer. There was a comparatively high prevalence of tobacco smoking in this cohor ${ }^{2223}$ so that increases in the incidence of lung cancer would be expected to occur earlier rather than later after first exposure.

Mortality from malignant pleural mesothelioma increased significantly with both duration of employment and time since first employment. There was also weak evidence of an effect of intensity of exposure but this effect was not statistically significant. The increase in mortality with time since first employment agreed well with the model postulated by Peto, ${ }^{1}$ relative rates increasing approximately with the third power of years since first employment. The effect of duration of employment showed some departure, which approached statistical significance, from the proposed log linear relation with an apparent "stepfunction" increase in relative risk after more than six months exposure. Analysis of data from further follow up will be needed to evaluate the importance of this observation.

An alternative model has been suggested where the quartic time terms in equation [2] are replaced by cubic terms lagged 10 years, arguing the existence of an arbitrary 10 year "latent period." Peto has argued persuasively against the concept of a latent period, showing that the reason for a lack of cases early after exposure is simply the low probability of any cases occurring in the early period. ${ }^{24}$ The evidence of this study is consistent with the formulation presented above. Other questions regarding, for example, the form of the dose response relation at low and high doses for both mesothelioma and lung cancer ${ }^{37}$ still need to be answered.

Mortality from stomach cancer bore no relation to intensity of exposure, duration of employment, or time since employment began. There was weak evidence that it was higher in those employed in the mine than in those employed at other sites. These results agree with a recent review which concluded that asbestos workers are not at an increased risk of gastrointestinal cancer because of their exposure to asbestos. ${ }^{25}$ Others have reached similar conclusions, ${ }^{6}$ although the reason for the increased death rates from gastrointestinal cancer in this and other cohorts is still not clear. Misdiagnosis of peritoneal mesothelioma suggested by some ${ }^{6}$ as a possibility was discounted in this cohort by confirming the pathological basis of the diagnosis in all 13 of the 17 cases where this was possible.' The lack of convincing evidence of a dose response relation still points to selection bias (or noncomparability of comparison groups in SMR calculations) as the most likely explanation.

In this and many other cohort studies of exposure to asbestos measurement of the duration of exposure is known much more accurately than the intensity of exposure. ${ }^{26}$ Fibre counts were only taken in the one survey shortly before the mine and mill ceased operations. Anecdotal evidence suggests that earlier measurements would have been much higher and although this has been partially allowed for by using the subjective ranking, there is certain to be a large degree of error. As long as the errors in measurement are random, this will bias estimated relative risks towards unity, ${ }^{27}$ and the larger the error the greater this attenuation will be. It is therefore quite likely that the estimated odds ratios for intensity of exposure presented here are too low. It is much less likely that those for duration of exposure or time since first exposure are biased. This appears the most likely explanation of the lack of an apparent effect of intensity of exposure on mesothelioma mortality as well as the seemingly greater effect of duration of exposure than of intensity of exposure on lung cancer mortality (fig 1).

Incompleteness of follow up and the assumption that those not known to be dead or departed overseas are still alive appeared preferable to the alternative of censoring at the date last known to be alive because of the association between loss to follow up and both 
intensity and duration of exposure. The extent of this dependency was shown previously with $67 \%$ follow up in those employed less than three months compared with $93 \%$ for those employed for more than five years. ${ }^{9}$ For intensity of exposure the effect was reversed with $79 \%$ follow up in those exposed to $5 \mathrm{f} / \mathrm{ml}$ or less compared with $73 \%$ follow up in those exposed to more than $50 \mathrm{f} / \mathrm{ml}$ (all millworkers). The biasing effect of removing all those lost to follow up is also likely to be increased by the greater likelihood of tracing someone who is dead than someone still alive given the generally higher rate of mortality among short stay workers. ${ }^{19}$ Because of the methods of tracing, with accurate death and cancer registry records being the most reliable sources of information, it is unlikely that any deaths from pleural mesothelioma or more than a few from either lung cancer or stomach cancer have been missed. The effect therefore of loss to follow up on the estimates should be only slight. Other workers have chosen the alternative approach of censoring at the date of loss to follow up, ${ }^{28}$ which has prompted some discussion, ${ }^{27}{ }^{29}$ but it seems that no generally applicable conclusions can be drawn.

The effect of lack of information about smoking habits on the estimated odds ratios for lung cancer is hard to judge. It is unlikely that smoking habit was associated with either duration or intensity of exposure to asbestos, given the comparatively short periods of employment, so that these estimates should be unaffected. The effects of both nationality and years since first employed are likely to differ when allowing for smoking habit. These problems will be examined more closely in future studies of a subgroup of workers who completed a detailed questionnaire in 1979 on smoking habits and occupation.

This study of men exposed exclusively to crocidolite asbestos for generally short periods at high levels has shown clear relations between quantitative and temporal measures of exposure to crocidolite and subsequent mortality from malignant mesothelioma of the pleura and lung cancer. The forms of these relations are consistent with those previously proposed' but with some discrepancies. It is hoped that these discrepancies may be clarified with the increased number of events available from follow up to the end of 1986.

\section{References}

1 Peto J. Problems in dose response and risk assessment: the example of asbestos. Banbury Report 1985;19:89-97.

2 Nicholson WJ. Asbestos health effects update (review draft). Washington: Environmental Protection Authority, 1983.

3 World Health Organisation. Asbestos and other natural mineral fibres. Geneva: WHO, Environmental health criteria, 1986.

4 Hughes JM, Weill $\mathrm{H}$. Asbestos esposure-quantitative assessment of risk. Am Rev Respir Dis 1986;133:5-13.

5 Ohlson C-G, Hogstedt C. Lung cancer among asbestos cement workers. A Swedish cohort study and a review. Br J Ind Med 1985;42:397-402.

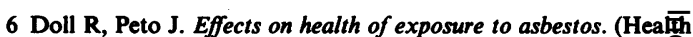
and Safety Commission). London: HMSO, 1985.

7 Hughes JM, Weill H, Hammad YY. Mortality of work employed in two asbestos cement manufacturing plants. $B \Omega$ Ind Med 1987;44:161-74.

8 Cullen MR. Controversies in asbestos-related lung cancer. State $\overrightarrow{\overrightarrow{\partial f}}$ the Art Review of Occupational Medicine 1987;2:259-72.

9 Armstrong BK, de Klerk NH, Musk AW, Hobbs MST. Mortal跑 in miners and millers of crocidolite in Western Australia. $B$ ] Ind Med 1988;45:5-13.

10 Hobbs MST, Woodward SD, Murphy B, Musk AW, Elder JT. The incidence of pneumoconiosis, mesothelioma and other respiratory cancer in men engaged in mining and millif crocidolite in Western Australia. In: Wagner JC, ed. Biological effects of mineral fibres. Lyon: International Agency Research on Cancer, 1980:615-25.

11 Botha JL, Irwig LM, Strebel PM. Excess mortality from stomacb cancer, lung cancer and asbestosis and/or mesothelioma 由 crocidolite mining districts in South Africa. Am J Epidem 1986;123:30-40.

12 Enterline PE, Hartley J, Henderson V. Asbestos and cancer: cohort followed up to death. Br J Ind Med 1987;44:396-401. \%

13 Finkelstein MM. Mortality among employees of an Ontare asbestos-cement factory. Am Rev Respir Dis 1984;129:754-6

14 Breslow NE, Day NE. The standardised mortality ratio. In: Seg PK, ed. Biostatistics: statistics in biomedical, public health and environmental sciences, New York: Elsevier, 1985:55-74.

15 Liddel FDK, Hanley JA. Relationships between asbestos exposure and lung cancer SMRs in occupational cohort studies. $\mathrm{Br} J$ I Med 1985;42:389-96.

16 Major G. Asbestos dust exposure. In: Major G, ed. Proceedings र्लf the first Australian pneumoconiosis conference, Sydney, 1968 Sydney: Joint Coal Board, 1968:467-74.

17 Breslow NE, Lubin JH, Marek P, Langholz B. Multipliçatif, models and cohort analysis. Journal of the American Statisica Association 1983;78:1-12.

18 McCullagh P, Nelder JA. Generalised linear models. Lom Chapman and Hall, 1983.

19 Breslow NE, Day NE. Statistical methods in cancer research. $\overrightarrow{\text { Vol}} \mid \overline{\bar{g}}$ The design and analysis of cohort studies. Lyon: Internationa Agency for Research on Cancer, 1987.

20 Peto J, Doll R, Hermon C, Binns W, Clayton R, Goffe I Relationship of mortality to measures of environmental asber. tos pollution in an asbestos textile factory. Ann Occup $\mathrm{H}_{8}$ 1985;29:305-55.

21 Walker AM. Declining relative risks for lung cancer after cessati of asbestos exposure. J Occup Med 1984;26:421-6.

22 Baker JE. Lung cancer incidence amongst previous employees of asbestos mine in relationship to crocidolite exposure and tobacco smoking. Perth: University of Western Australia, 1985. (PhD thesis.)

23 Cookson WO, de Klerk NH, Musk AW, Armstrong BǨ Glancy JJ, Hobbs MST. The prevalence of radiograph asbestosis in crocidolite miners and millers at Wittenoom Western Australia. Br J Ind Med 1986;43:450-7.

24 Peto J. Some problems in dose-response estimation in cance epidemiology. In: Vouk VB, Butler GC, Hoel DG, Peakall DB; eds. Methods for estimating risk of chemical injury: human and non-human biota and ecosystems. New York: Wiley, 1985.

25 Edelman DA. Exposure to asbestos and the risk of gastrointestinas cancer: a reassessment. Br J Ind Med 1988;45:75-82.

26 Greenland $S$. The effect of misclassification in the presence covariates. Am J Epidemiol 1980;112:564-9.

27 Johnson ES. Treatment of subjects lost to follow-up in the analysis of mortality studies. J Occup Med 1988;30:60-2.

28 Vena JE, Sultz HA, Carlo GL, Fiedler RC, Barnes RE. Sources of bias in retrospective cohort mortality studies: a note treatment of subjects lost to follow-up. J Occup Med 1989 29:256-61.

29 Savitz DA, Moure R. Treatment of subjects lost to follow-up effect on oil refinery cancer risks. J Occup Med 1988;30:89-9 